\title{
Bacterial Patterns and Sensitivity to Antibiotics in Patients Treated with Ventilators at the Intensive Care Unit of Sanglah Hospital Denpasar, Bali, Indonesia
}

\author{
Mark Kevin Devian*iD, I Wayan Suranadi (D), I Gusti Agung Gede Utara Hartawan (D), I Wayan Aryabiantara (D) \\ Department of Anesthesiology and Intensive Care, Faculty of Medicine, Udayana University, Bali, Indonesia
}

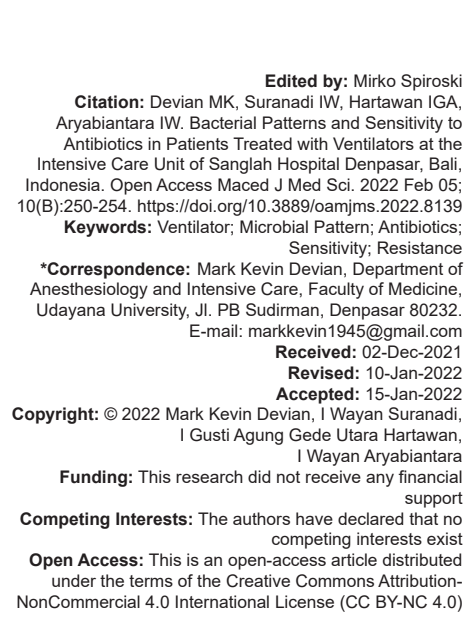

\section{Introduction}

Theintensivecareunit(ICU)isanindependentpart of a hospital with specialized medical staff and equipment that aims to treat patients in critical condition [1]. Critical patients' vital signs need to be monitored regularly as it has a high potential to deteriorate. In this case, one of the most common incidences is respiratory failure. To handle respiratory failure, the usage of a mechanical ventilator to maintain adequate oxygenation is crucial to prevent further organ damage [2]. However, maintaining the patient's patent airway using an endotracheal tube (ETT) is an invasive procedure, therefore, creating an entrance for microorganisms to infect and causing inflammation on the lung, this condition is called ventilator-associated pneumoniae (VAP) [3]. Research in 2018 showed that usage of the right intravenous antibiotic prophylaxis can significantly decrease the incidence of early onset VAP in comatose patients [4]. On the other hand, irrational usage of antibiotics can increase the incidence of multidrugresistant organisms (MDRO) infection that contributes to high mortality in VAP patients [5]. Established knowledge on microbial patterns and antibiotic sensitivity found in patients treated with ventilators to provide antibiotics treatment considerations are still limited. Therefore, this study aims to obtain more data linked to the microbial pattern, its antibiotic sensitivity, and resistance in patients treated ventilators within the ICU of Sanglah Hospital Bali.

\section{Subjects and Methods}

This retrospective study is conducted based on a cross-sectional descriptive method and was 
ethically approved by Sanglah General Hospital's Research Ethics Committee (411/UN14.2.2.VII.14/ LT/2021). Samples for this research were chosen through consecutive sampling method using patient's medical records in Sanglah General Hospital registry from January 1, 2021 until June 30, 2021 within the ICU of Sanglah Hospital Denpasar. The sample population consists of patients that have a complete medical record, are treated with mechanical ventilation, and have a positive bacterial culture test. The subjects' bacterial culture, sensitivity, and resistance results were obtained from Sanglah General Hospital's Clinical Microbiology Department Laboratory. The data collected were analyzed univariately using Microsoft Excel. The collected variables were listed as followed: Demographic data of the patients that include age, gender, comorbid, diagnosis, ventilator usage indication, bacterial culture, and bacterial susceptibility test.

\section{Results}

A total of 113 patients' medical records were collected. The sample consists of $45(39.8 \%)$ females and $68(60.2 \%)$ males. The mean age for the sample was $50.2 \pm 17.6$. Indications of ventilator usage in the ICU are dominated by post-operative patients (55.8\%). ETT sputum sample is the highest amount of bacterial culture samples type that was collected (Table 1).

Table 1: Subjects' characteristics

\begin{tabular}{ll}
\hline Characteristics & $\mathrm{n}=113$ \\
\hline Sex, $\mathrm{n}(\%)$ & \\
Male & $68(56.6)$ \\
Female & $45(43.4)$ \\
Age (years) & \\
Mean \pm SD & $50.2 \pm 17.06$ \\
Min-max & $16-85$ \\
Ventilator Indication & \\
Respiratory failure & $14(12.4)$ \\
Pneumonia & $4(3.5)$ \\
Neuromuscular disorder & $1(0.8)$ \\
Sepsis & $8(7.1)$ \\
Decrease of consciousness & $15(13.3)$ \\
ARDS & $5(4.4)$ \\
Lung nodule & $2(1.8)$ \\
Lung edema & $1(0.6)$ \\
Post-operative respiratory insufficiency & $63(55.8)$ \\
Culture type & \\
Sputum & $34(18.4)$ \\
Tube Sputum & $94(50.8)$ \\
ETT Sputum & $11(5.9)$ \\
Blood & $46(24.9)$ \\
\hline SD: Standard deviation, min-max: Minimum-maximum &
\end{tabular}

Out of 113 patients, we managed to obtain 185 positive bacterial culture results. Overall, the most common microorganism found was Gram-negative bacteria with the three highest percentages that are Pseudomonas aeruginosa (22.2\%), Acinetobacter baumanii $(20 \%)$, and Klebsiella pneumoniae (17.3\%) (Table 2). We also found some MDRO in the bacterial pattern with MDR-K. pneumoniae as the highest figure to have presented (Figure 1).

In this study, we analyzed the bacterial susceptibility using univariate analysis with samples
Table 2: Bacterial pattern

\begin{tabular}{ll}
\hline Bacterial species & $\mathrm{n}(\%)$ \\
\hline Pseudomonas aeruginosa & $41(22.2)$ \\
Acinetobacter baumanii & $37(20)$ \\
Klebsiella pneumoniae & $31(17.3)$ \\
Eschericia coli & $19(10.3)$ \\
Staphylococcus aureus & $11(5.9)$ \\
Enterobacter cloacae & $11(5.9)$ \\
Staphylococcus hominis & $6(3.2)$ \\
Staphylococcus epidermidis & $5(2.7)$ \\
Staphylococcus maltophilia & $4(2.2)$ \\
Staphylococcus haemoliticus & $3(1.6)$ \\
Citrobacter koseri & $2(1.1)$ \\
Citrobacter freundii & $1(0.5)$ \\
Streptococcus anginosus & $1(0.5)$ \\
Streptococcus alactolyticus & $1(0.5)$ \\
Streptococcus suis I & $1(0.5)$ \\
Enterobacter faecalis & $2(1.1)$ \\
Enterococcus columbae & $1(0.5)$ \\
Acinetobacter spp. & $3(1.6)$ \\
Vibrio mimicus & $1(0.5)$ \\
Serratia marcescens & $1(0.5)$ \\
Total & $185(100)$ \\
\hline &
\end{tabular}

taken from the three most common organisms found within the bacterial pattern (Table 2). Our research shows $P$. aeruginosa that has the highest bacterial percentage mostly sensitive to ceftazidime (68.3\%), gentamicin $(68.3 \%)$, and amikacin $(65.9 \%)$, the prevalence of the two following bacteria, which are $A$. baumanii $(56.8 \%)$ and $K$. pneumoniae $(83.9 \%)$, shared the sensitivity toward amikacin. The resistance pattern of $P$. aeruginosa and $A$. baumanii shared similar resistance prevalence to cefixime. However, K. pneumoniae is mostly resistant to ciprofloxacin (61.3\%) (Table 3$)$.

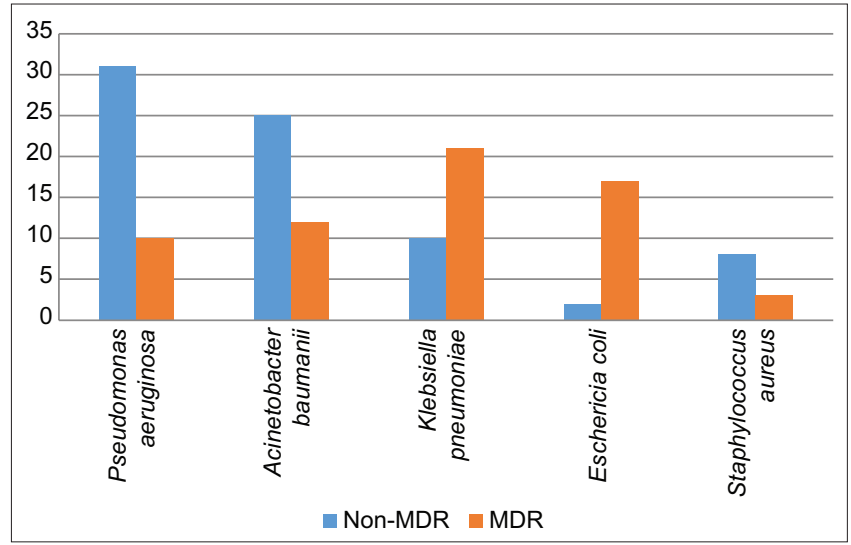

Figure 1: Prevalence of multidrug resistant organism in ventilated patient

\section{Discussion}

\section{Ventilated subject characteristics}

In this research, it is shown that males (56.6\%) are more commonly treated with ventilators in the ICU and could be considered compatible with another research in Thailand [6]. The main indications of ventilator usage mentioned in Table 1, which are postoperative patients that suffer respiratory insufficiency, having a decrease of consciousness, and acute respiratory failure also shared a similar result with the indication of mechanical ventilation treatment in Poland [7]. The resulting male predominance can be 
supported by a study in 2018 that mentioned a higher chance of males to experience morbidities, such as cardiac and respiratory complications after receiving operative procedures [8].

Table 3: Bacterial susceptibility test result

\begin{tabular}{|c|c|c|c|c|c|c|c|}
\hline \multirow[t]{2}{*}{ S. No. } & \multirow[t]{2}{*}{ Antibiotics } & \multicolumn{2}{|c|}{$\begin{array}{l}\text { Pseudomonas } \\
\text { aeruginosa } \\
(\mathrm{n}=41)\end{array}$} & \multicolumn{2}{|c|}{$\begin{array}{l}\text { Acinetobacter } \\
\text { baumanii } \\
(\mathrm{n}=37)\end{array}$} & \multicolumn{2}{|c|}{$\begin{array}{l}\text { Klebsiella } \\
\text { pneumoniae } \\
(\mathrm{n}=31)\end{array}$} \\
\hline & & S (\%) & $\mathrm{R}(\%)$ & S (\%) & $\mathrm{R}(\%)$ & S (\%) & $\mathrm{R}(\%)$ \\
\hline 1. & Piperacillin/Tazobactam & 58.5 & 22 & 13.5 & 75.7 & 54.8 & 6.5 \\
\hline 2. & Ampicillin/Sulbactam & 0 & 0 & 21.6 & 62.2 & 29 & 35.5 \\
\hline 3. & Cefoperazone/Sulbactam & 0 & 2.4 & 2.7 & 5.4 & 6.5 & 0 \\
\hline 4. & Cefazolin & 0 & 58.5 & 0 & 51.4 & 3.2 & 6.5 \\
\hline 5. & Cefuroxime & 0 & 58.5 & 2.7 & 43.2 & 3.2 & 0 \\
\hline 6. & Cefoxitin & 0 & 2.4 & 0 & 0 & 0 & 0 \\
\hline 7. & Ceftazidime & 68.3 & 19.5 & 8.1 & 51.4 & 9.7 & 0 \\
\hline 8. & Ceftriaxone & 0 & 4.9 & 0 & 67.6 & 29 & 16.1 \\
\hline 9. & Cefotaxime & 0 & 2.4 & 5.4 & 2.7 & 3.2 & 0 \\
\hline 10. & Cefoperazone & 2.4 & 0 & 0 & 81.1 & 0 & 0 \\
\hline 11. & Cefixime & 0 & 70.7 & 0 & 86.5 & 25.8 & 3.2 \\
\hline 12. & Cefepime & 63.4 & 17.1 & 24.3 & 70.3 & 32.3 & 12.9 \\
\hline 13. & Ampicillin & 0 & 0 & 2.7 & 0 & 3.2 & 6.5 \\
\hline 14. & Gentamicin & 68.3 & 19.5 & 32.4 & 62.2 & 51.6 & 35.5 \\
\hline 15. & Amikacin & 65.9 & 22 & 56.8 & 24.3 & 83.9 & 3.2 \\
\hline 16. & Tigecyline & 0 & 46.3 & 32.4 & 10.8 & 9.7 & 3.2 \\
\hline 17. & Ciprofloxacin & 63.4 & 26.8 & 18.9 & 73 & 22.6 & 61.3 \\
\hline 18. & Ofloxacin & 0 & 0 & 0 & 0 & 0 & 0 \\
\hline 19. & Levofloxacin & 36.6 & 34.1 & 24.3 & 24.3 & 16.1 & 48.4 \\
\hline 20. & Meropenem & 53.7 & 3.2 & 21.6 & 59.5 & 77.4 & 3.2 \\
\hline 21. & Cotrimoxazole & 0 & 35.5 & 59.5 & 27 & 32.3 & 35.5 \\
\hline 22. & Colistin & 0 & 2.4 & 2.7 & 0 & 0 & 0 \\
\hline
\end{tabular}

\section{Bacterial pattern in ventilated patients}

The bacterial pattern in our study is dominated by Gram-negative bacteria (GNB), such as $P$. aeruginosa (22.2\%), A. baumanii (20\%), K. pneumoniae $(17.3 \%)$, and Eschericia coli $(10.3 \%)$. This finding is supported by the 2016 American Thoracic Society (ATS) guideline that mentioned similar pathogens as the cause of VAP [9]. The studies have also shown that $P$. aeruginosa infections in VAP are highly related to empirical use of antibiotics and the usage of mechanical ventilation for more than 5 days [10]. Infection of GNB is higher since they are more likely to develop into MDRO. This is caused by its ability to alter its outer layer, such as mutating the porins and hydrophobic layer, therefore, disturbing antibiotics adherence and diffusion into the microorganism [11]. Findings of MDRO in bacterial patterns need to be observed closely since it is a significant variable that contributes to patients' length of stay, cost of treatment, and mortality in the ICU [12]. In combating MDRO, ATS published a guideline that proved consistent relation of prior antibiotics treatment resulting infection of MDR pathogens in VAP. It is also mentioned that preventing the spread of MDRO in invasive ventilated patients can be achieved by considering intubation alternatives, usage of silver-coated ETT and subglottic secretion drainage ETT, and building antibiotic stewardship in the health facilities [13].

\section{Bacterial susceptibility}

This study analyzed bacterial sensitivity and resistance from the three most common bacteria that we found in our samples as shown in (Table 3).
$P$. aeruginosa is mostly sensitive to ceftazidime (68.3\%), gentamicin (68.3\%), and amikacin (65.9\%). This pattern is similar to research by Widyaningsih that found $P$. aeruginosa sensitivity toward ceftazidime, gentamicin, and netilmicin [14]. Ceftazidime high sensitivity against $P$. aeruginosa compared to the other third generation of cephalosporins is supported by research conducted in Pakistan that collect samples from hospitals isolates [15] and another research by Rhodes that shown above $60 \%$ isolates of $P$. aeruginosa to be sensitive toward ceftazidime and cefepime, therefore, supported the antibiotics recommendation in the 2016 ATS guideline [16]. We also found that A. baumanii isolates are mostly sensitive to amikacin (56.8\%), gentamicin (32.4\%), and tigecyline (32.4\%). Finally, K. pneumoniae found to be sensitive toward amikacin $(83.9 \%)$, meropenem $(77.4 \%)$, piperacillin/ tazobactam (54.8\%), and gentamicin (51.6\%). Overall, amikacin and gentamicin are still sensitive to these three bacteria; this is similar to a study in Nepal that showed amikacin sensitivity to $58 \%$ of the isolates (K. pneumonia, Acinetobacter spp., and $P$. aeruginosa) in VAP patients [17]. A study in China has evaluated the usage of amikacin and proved even better results against GNB, such as E. coli, $P$. aeruginosa, and K. pneumoniae but in contrast, the research stated low sensitivity of amikacin against MDR-A. baumanii [18]. This sensitivity result may also be caused by unfavorable use of aminoglycosides monotherapy concerning the antibiotic's low lung penetration and worrying adverse effects as stated by the ATS panel. However, more studies are needed to evaluate this statement [9].

\section{Bacterial resistance}

Our research found the bacterial resistance pattern (Table 3 ) with $P$. aeruginosa isolates is mostly resistant toward cefixime $(70.7 \%)$, cefazolin $(58.5 \%)$, and cefuroxime $(58.5 \%), A$. baumanii isolates mostly resistant to cefixime (86.5\%), cefoperazone $(81.1 \%)$, and piperacillin/tazobactam (75.7\%). This finding is supported by another research in Indonesia that found nearly identical bacterial patterns in VAP to be most resistant toward cephalosporins (cefixime, cefotaxime, and ceftriaxone) [19]. We also found that $K$. pneumoniae isolates to be resistant to ciprofloxacin $(61.3 \%)$ and levofloxacin $(48.4 \%)$. It can be concluded that extended spectrum beta-lactamases (ESBL) and AmpC-beta lactamases (AmpC) producers bacteria that are commonly developing resistance to cephalosporins and penicillins have a high contribution to this resistance pattern (Figure 1) [20], [21]. There is still a lack of study recommending treatment to fight ESBL/AmpC producers in ventilated patients. However, the use of carbapenems may be a preferable option [22], [23]. In addition, the ATS guideline recommends the use of vancomycin and linezolid for empirical treatment if the bacterial pattern indicates findings of methicillin-resistant 
Staphylococcus aureus and other MDR bacteria which were also presented in this study (Figure 1).

\section{Conclusion}

Nosocomial infections associated with mechanical ventilation caused by MDRO remain a problem toward patients' outcome in the ICU. For that reason, intensivists need to adjust the right use of antibiotics and further prevention strategies for VAP according to the updated bacterial patterns and sensitivity tests results that are available.

\section{References}

1. Marshall J, Bosco L, Adhikari N, Connolly B, Diaz J, Dorman T, et al. What is an intensive care unit? A report of the task force of the world federation of societies of intensive and critical care medicine. J Crit Care. 2017;37:270-6. https://doi.org/10.1016/j. jcrc.2016.07.015

PMid:27612678

2. Mujahidin M. Extra corporeal membrane oxygenation (ECMO) pada pasien extra corporeal membrane oxygenation (ECMO) adult. J Anestesi Indones. 2016;8(3):151.

3. Pham T, Brochard L, Slutsky A. Mechanical ventilation: State of the art. Mayo Clin Proc. 2017;92(9):1382-400. https://doi. org/10.1016/j.mayocp.2017.05.004

PMid:28870355

4. Mirtalaei N, Farazi A, Monfared ME, Jokar A. Efficacy of antibiotic prophylaxis against ventilator-associated pneumonia. J Hosp Infect. 2018;101(3):272-5. https://doi.org/10.1016/j. jhin.2018.08.017

PMid:30179656

5. Kumari M, Rastogi N, Malhotra R, Mathur P. Clinicomicrobiological profile of healthcare associated pneumonia in critically ill patients at level-I trauma centre of India. J Lab Physicians. 2018;10(4):406-9. https://doi.org/10.4103/JLP. JLP_85_18

\section{PMid:30498312}

6. Saiphoklang $N$, Kanitsap A, Ruchiwit $P$, Pirompanich $P$ Sricharoenchai T, Cooper C. Patient characteristics and outcomes of a home mechanical ventilation program in a developing country. Lung India. 2019;36(3):207-201. https://doi. org/10.4103/lungindia.lungindia_219_18

PMid:31031340

7. Kubler A, Maciejewski D, Adamik B, Kaczorowska M. Mechanical ventilation in ICUs in Poland: A multi-center point-prevalence study. Med Sci Monit. 2013;19:424-9. https://doi.org/10.12659/ MSM.883930

PMid:23727991

8. Al-Taki M, Sukkarieh $\mathrm{H}$, Hoballah J, Jamali $\mathrm{S}$, Habbal $M$, Masrouha $\mathrm{K}$, et al. Effect of gender on postoperative morbidity and mortality outcomes: A retrospective cohort study. Am Surg. 2018;84(3):377-86.

PMid:29559052

9. Kalil A, Metersky M, Klompas M, Muscedere J, Sweeney D,
Palmer L, et al. Management of adults with hospital-acquired and ventilator-associated pneumonia: 2016 Clinical practice guidelines by the infectious diseases society of america and the American thoracic society. Clin Infect Dis. 2016;63(5):e61-111. https://doi.org/10.1093/cid/ciw353

PMid:27418577

10. Rello J, Ramirez Estrada S, Borgatta B. Pseudomonas aeruginosa ventilator-associated pneumonia management. Infect Drug Resist. 2016;9:7-18. https://doi.org/10.2147/IDR. S50669

PMid:26855594

11. Exner M, Bhattacharya S, Chrstiansen B, Gebel J, GoroncyBermes P, Hartemann P, et al. Antibiotic resistance: What is so special about multidrug-resistant Gram-negative bacteria? GMS Hyg Infect Control. 2017;12(5):Doc05. https://doi.org/10.3205/ dgkh000290

PMid:28451516

12. Zhou Y, Yu F, Yu Y, Zhang Y, Zhang Y. Clinical significance of MDRO screening and infection risk factor analysis in the ICU. Am J Transl Res. 2021;13(4):3717-23.

PMid:34017556

13. Grgurich P, Hudcova J, Lei Y, Sarwar A, Craven D. Management and prevention of ventilator-associated pneumonia caused by multidrug-resistant pathogens. Exp Rev Respir Med. 2012;6(5):533-55. https://doi.org/10.1586/ers.12.45 PMid:23134248

14. Widyaningsih R, Buntaran L. Bacterial Patterns of Ventilator Associated Pneumonia (VAP) and Sensitivity towards Antibiotics at RSAB Harapan Kita. Sari Pediatri. 2016;13(6):384.

15. Ullah H, Javeid I, Khalid K, Muhammad H, Sahrish J. Ullah HA et al. In vitro comparative study of cefoperazone, ceftazidime, ceftizoxime, cefotaxime, ceftriaxone and cefixime against pseudomonas aeruginosa. Int Res J Pharm. 2013;4(1):136.

16. Rhodes N, Cruce C, O'Donnell J, Wunderink R, Hauser A. Resistance trends and treatment options in gramnegative ventilator-associated pneumonia. Curr Infect Dis Rep. 2018;20(2):3. https://doi.org/10.1007/s11908-018-0609-x PMid:29511909

17. Mishra D, Shah D, Shah N, Prasad J, Gupta P, Agrawaal K Study of microbiological and antibiotic sensitivity pattern of ventilator associated pneumonia (VAP) in ICU of a tertiary care hospital in Nepal. J Family Med Prim Care. 2020;9(12):6171-6. https://doi.org/10.4103/jfmpc.jfmpc_1430_20

PMid:33681059

18. Kuti JL, Wang Q, Chen H, Li H, Wang H, Nicolau D. Defining the potency of amikacin against Escherichia coli, Klebsiella pneumoniae, Pseudomonas aeruginosa, and Acinetobacter baumannii derived from Chinese hospitals using CLSI and inhalation-based breakpoints. Infect Drug Resist. 2018;25(11):783-90. https://doi.org/10.2147/idr.s161636 PMid:29872328

19. Shodikin M, Ramadhanty M, Semita I. Bacterial identification and antibiotics sensitivity of ventilator-associated pneumonia (VAP) patients at RSD Dr. Soebandi Jember. J Health Sci. 2021;14(2):103-11. https://doi.org/10.33086/jhs.v14i02.1891

20. Luyt C, Sahnoun T, Gautier M, Vidal P, Burrel S, de Chambrun MP, et al. Ventilator-associated pneumonia in patients with SARS-CoV-2-associated acute respiratory distress syndrome requiring ECMO: A retrospective cohort study. Ann Intensive Care. 2020;10(1):158. https://doi. org/10.1186/s13613-020-00775-4

PMid:33230710

21. Herdwiyanti M, Alisjahbana B, Santoso P. Patterns and Sensitivity of Sputum Bacterial Culture and The Characteristics of Pneumonia Patients in RSUP Dr. Hasan Sadikin Bandung. 
Tunas Med J Kedokteran Kesehatan. 2021;7(1):1-6.

22. Meini S, Tascini C, Cei M, Sozio E, Rossolini G. AmpC $\beta$-lactamase-producing Enterobacterales: What a clinician should know. Infection. 2019;47(3):363-75. https://doi. org/10.1007/s15010-019-01291-9

PMid:30840201
23. Tsai H, Chen Y, Tang H, Huang C, Liao C, Chu F, etal. Carbapenems and piperacillin/tazobactam for the treatment of bacteremia caused by extended-spectrum $\beta$-lactamase-producing Proteus mirabilis. Diagn Microbiol Infect Dis. 2014;80(3):222-6. https:// doi.org/10.1016/j.diagmicrobio.2014.07.006

PMid:25139843 